\title{
Transforming theory into practice \\ Creating student-centered instructional activities rooted in the Framework
}

D uring summer 2019, the four reference librarians at the University of the District of Columbia (UDC), an HBCU in the nation's capital, met weekly to review and discuss each part of the ACRL Framework for Information Literacy for Higher Education. With our student population in mind, we had two goals: establishing a team-wide shared analysis of each frame and developing a collection of student-centered active learning activities, rooted in the Framework's concepts, that could be mixed and matched during one-shot and embedded library instruction. Prior to this project, the librarians were using a limited group of library instruction activities that were not necessarily related to the Framework. During the project, the librarians found the Framework to be highly theoretical, making it challenging to identify concrete learning activities. However, by deeply engaging with the Framework, it was possible to create student-centered instructional activities that were rooted in the theory, and we were able to expand our repertoire of activities used in library instruction. We were also able to provide faculty with firm examples of how library instruction engages their students in information literacy and lifelong learning.

\section{Process}

The team met for two hours on Fridays for six weeks over the summer, a quieter time at the library, dedicating one session to each frame. In preparation for each meeting, we individually reviewed the text of the frame in depth and read the "Recommended Resources, Readings, and Examples" for that frame in 23 Framework Things. ${ }^{1}$ Additionally, everyone prepared for the meeting by developing a variety of ideas for activities tied to the frame. They could be fully developed activities found in Project CORA or the ACRL Sandbox, adaptations of existing activities, or a tiny kernel of an idea.

In each meeting, we discussed the frame, reviewed activity ideas, and decided on three activity concepts that each librarian wanted to develop further. In discussing each of the frames, we had the opportunity to share ways in which we already addressed this frame in instruction, challenges we had in incorporating this frame, and resolve personal questions we had about the frame. It also allowed for collaborative discussion of activity ideas, regardless of their stage of development. At the end of each meeting, each librarian selected three activity ideas to fully develop using a template, to build a shared bank of activities for each frame that ranged from beginner to developing to advanced. It was not uncommon for a librarian to select someone else's idea to develop further. This collaborative approach

\footnotetext{
Meghan Kowalski is outreach and reference librarian at the University of the District of Columbia, email: meghan.kowalski@udc.edu, Catherine Meals is assessment and reference librarian at the University of the District of Columbia, email: catherine.meals@ udc.edu, and Faith Rusk, formerly information literacy instruction librarian at the University of the District of Columbia, is now health and life sciences librarian at San Francisco State University, email:frusk@sfsu.edu
}

๑ 2021 Meghan Kowalski, Catherine Meals, and Faith Rusk 
was important because all librarians teach across subject areas and regularly teach different sections of the same course. As an activity was developed, it was shared with the group for feedback, but no timeline was set for this work. Full development sometimes happened at the point of need when it felt like a good fit for a class.

\section{Activity examples}

Our sessions were helpful in situating many of our existing classroom activities within one or more frames, but, more importantly, we developed and adapted several new (or new to us) classroom activities based on our reflection and discussions. For instance, we adapted the Sphere of Discourse activity, which involves tossing around a beach ball, found on Project CORA. ${ }^{2}$ We experimented with this activity in multiple classes as a means to discuss formats, values, and evaluation of information (Authority is Constructed and Contextual and Information Has Value). Feedback was uniformly positive, describing it as a fun and unexpected way to learn, though we believe it was most impactful in classes with long-term interdisciplinary research projects, where students are explicitly required to incorporate a variety of source types in their research.

After discussing the frame Authority is Constructed and Contextual, we decided we wanted to modify our existing approach to discussing evaluating sources to make it a more studentdirected activity. While we had previously used a CRAAP test checklist, instead we began asking students "What do you think makes a source 'good'?" Students often describe all information as good or bad regardless of the context in which they plan to use it. ${ }^{3}$ Reframing the activity and discussing the importance of context and information need provided a better foundation for understanding the contextual nature of authority and emphasized their own existing knowledge and authority. Students identified characteristics of information-often the same ones contained in the CRAAP test-and applied the characteristics they have identified to sources distributed in class. Through the resulting discussion, students explored the nuances and contextuality of authority and weren't confined to a checklist. We have some activities still in development, including a card game modeled on the game Superfight ${ }^{4}$ for discussing the Authority is Constructed and Contextual and Information Has Value frames. In addition to activities, we developed digital learning objects. For example, to support the development of student dispositions in the Research as Inquiry frame, we developed a video tutorial on exploration and persistence in research. ${ }^{5}$

\section{Discussion}

UDC is an HBCU with a nontraditional student population. Many students are older, or part-time, and students often have full-time jobs or are caregivers. It also has a very large international student population and is an entirely commuter campus. When analyzing the Framework, we paid particular attention to the specific needs of our students. Our university's strategic plan, The Equity Imperative, ${ }^{6}$ puts lifelong learning at the forefront of its mission. We thus sought to develop lessons that fostered this drive by emphasizing activities that drew from lived experience in addition to classroom learning. We found that communicating with students on a more personal level and drawing connections between their real-life information use and the academic research context helped them engage more fully with the Framework theories that the activities supported.

However, the theoretical nature of the Framework and overlap among frames frequently made it difficult to develop concrete lessons. The Framework uses vocabulary like "understand," "recognize," and "acknowledge" to showcase broad aspects of information literacy that do not easily translate to classroom activities. Given the complexity of information literacy learning, it is difficult to teach a single frame, let alone the entire Framework, in a one-shot instruction session such as the ones we most commonly teach. Our reflections reinforced that, while the Framework seeks to provide direction and outcomes, it cannot, alone and in and of itself, be used as a tool for classroom instruction. Librarians must translate the document into lessons or activities appropriate to institutional settings and student needs. 
During our analysis, we also found that the Framework appears to presume at least a fundamental level of information literacy education and is harder to apply in practice for novice instruction. Since many of our students come to the classroom with limited experience in academic research and information literacy, we struggled to develop activities that engaged students in building a foundation for academic research. Many of the activity ideas that most appealed to us would be most appropriate and engaging for advanced learners, yet we have been unable to put the activities into practice, since most of our current instruction occurs in introductory or general education classes.

Further, we also identified many interesting activities that addressed information literacy writ large but did not serve the academic research skills that faculty expect us to teach, or the limited range of content that faculty expect that we are equipped to teach (e.g., "show students how to use the databases"). Faculty want their students to be able to do research, yet librarians view information literacy as the ultimate goal. In engaging deeply with the Framework, we saw clearly that research skills and information literacy are not the same thing. Many pieces of the Framework that we were excited by and interested in teaching don't link easily to "teaching research" in our context and do not fit easily into "traditional" research assignments. By incorporating elements of the Framework, our instruction can expand faculty perception of what librarians can teach. Faculty have responded positively and are eager to engage further. This approach also helps us connect information literacy and academic work with students' lived experience and needs.

\section{Unexpected benefits}

While the Framework can be difficult to work with on an instructional level, it was a worthwhile endeavor for our instruction program. Furthermore, we found that this project provided two surprising additional benefits. First, we uncovered that by employing fun activities, we were able to alleviate some student anxiety around research and the library. Since our activities sought to directly engage students and their experience, we were able to more easily connect to them as individuals. We were often able to show students how they conduct research and develop information literacy skills in their daily lives. Additionally, it's hard to be too stressed when you're tossing a beach ball around a classroom.

The second benefit we encountered was a boost to our marketing and outreach. Since some of our new activities involved props, we were able to share images on our social media and reach students where they spend time. Posts like this demystify the library and research by showing that it can be fun and engaging. It also means the librarians get to have a bit of fun creating content.

\section{Strategic/future planning}

The project we undertook has also helped our team identify future goals for our library instruction program. Currently, nearly all our instruction occurs in one- or two-shot sessions, and no library instruction is required for any UDC classes. In reviewing frames one by one, we identified specific courses that we do not frequently teach but hope to expand into, since Framework concepts neatly mesh with course content. Further, our realizations that many of our activity ideas were more appropriate for intermediate and advanced instruction, and that there were many theories and ideas that we have not adequately incorporated into our teaching, have helped us articulate the need to build a comprehensive information literacy curriculum where Framework concepts can be scaffolded throughout undergraduate and graduate curricula. We hope that a future outcome of this project will be to have library instruction required by, and structured into, our general education classes in order to ensure all students receive instruction in information literacy. We would then be able to put the more advanced lessons we developed to use in higher-level subject coursework.

\section{Recommendations}

While each librarian on our team had individually engaged with the Framework, our team process allowed us to develop a shared

(continues on page 120) 
1-August 27, 2019, to 26\% during the period of September 1-October 31, 2019.

The successful implementation of a staff development program requires buy-in and support from leadership. Staff, particularly those who are nonexempt, cannot be expected to engage in professional development activities during unpaid time (lunch break or before/after regular shift), so engagement in these events must be supported as part of regular work time and expectations. One way to demonstrate leadership commitment to the program is to incorporate staff development activities into annual performance evaluation and goal setting. In our case, each staff member was encouraged to include a list of the sessions they attended with their performance evaluations, and two nonlibrarian staff members had the development and presentation of a Lunch and Learn as one of their goals for 2020 .

The existence of this program allowed us to be very adaptable when the Libraries closed in March 2020 due to the COVID-19 pandemic and all staff moved to remote work. Lunch and Learns and other trainings have continued on Zoom, and we have expanded to include topics and trainings related to use of Zoom, ready reference for virtual interactions, and digital projects.

In the library community there are an abundance of opportunities for one-off professional development in the form of conferences, webinars, and online courses. These are invaluable and important opportunities to encourage staff to take advantage of and attend. However, they should not be the only form of professional development that a library staff relies upon. Designing and implementing a structured program of staff development that incorporates the expertise of all staff, encourages social learning as a group, and adopts a variety of learning styles has proven a great way to develop a culture of learning, sharing, and professional growth.

\section{Notes}

1. https://researchguides.dartmouth.edu /consumer_health.

2. Materials from Lunch and Learn sessions that I have led are available in the Materials Folder linked in the notes.

3. OCLC WebJunction and IMLS, "Competency Index for the Library Field” (2014), https:// www.webjunction.org/documents/webjunction /Competency_Index_for_the_Library_Field.html.

4. PowerPoint presentations and other staff development program materials can be accessed at dartgo.org/staffdevelopment. All materials carry a Creative Commons Attribution-NonCommercial 4.0 International License.

("Transforming theory into practice," continued from page 116)

understanding of the theories and ideas of the Framework and what they mean for our students. As a result, the Framework has become more of a presence and touchstone in our instruction program, even as we recognize its limitations. While a project such as the one we completed will certainly be easier and more manageable for small teams of librarians, we believe its value was significant enough to warrant adaptation to other settings. Larger groups may consider conducting the process through a think-pair-share model, or in subject area teams, where the focus is applying the Framework to specific disciplinary approaches and needs.

\section{Notes}

1. Amy Mars, Kim Pittman, and Trent Brager, “23 Framework Things," accessed July 29, 2020, https://23frameworkthings.wordpress.com/.
2. Beth Hoppe, "Sphere of Discourse," uploaded February 18, 2020, https://www.projectcora.org/assignment/sphere-discourse.

3. Cathy Meals, "What Makes a Source 'Good," uploaded July 28, 2020, https://www. projectcora.org/assignment/what-makes-source -good.

4. Superfight is an Apples to Apples-style card game where participants create fighters from two sets of cards-characters and attributes-and then argue why their character would win in a fight.

5. UDC Library, "How to Solve the Goldilocks Research Problem," uploaded February 18, 2020, YouTube video, https://www.youtube.com /watch?v=t1LXD2jo5-o.

6. University of the District of Columbia, "The Equity Imperative," accessed July 29, 2020, https:// www.udc.edu/strategic-plan/. z 